\title{
FÍSICA MODERNA NO ENSINO MÉDIO: O ESPAÇO- TEMPO DE EINSTEIN EM TIRINHAS
}

\author{
Francisco Caruso \\ Centro Brasileiro de Pesquisas Físicas \\ Instituto de Física Armando Dias Tavares - UERJ \\ Nilton de Freitas ${ }^{1}$ \\ Instituto de Física Armando Dias Tavares - UERJ \\ Rio de Janeiro - RJ
}

\section{Resumo}

Faz-se um breve apanhado do impacto da contribuição de Einstein referente aos seguintes conceitos: espaço, tempo, simultaneidade, massa e energia. Apresentam-se alguns objetivos relacionados a um projeto de educação através de histórias em quadrinhos, no qual este trabalho se insere, e um conjunto de sete tirinhas originais, que pode ser utilizado pelos professores de Ensino Médio como suporte para uma abordagem lúdica e divertida da Física Moderna, evidenciando as contribuições de Einstein para a consolidação da importante revolução científica que foi a sua Teoria da Relatividade.

Palavras-chave: Espaço-tempo; Física; Educação em Ciência; Quadrinhos.

\footnotetext{
Abstract

A brief summary of the impact of Einstein's contribution concerning concepts like space, time, simultaneity, mass and

Modern Physics in High School: Space time in Einstein's comic strips
}

* Recebido: abril de 2008.

Aceito: março de 2009.

${ }^{1}$ Ex-bolsita da Faperj.

Cad. Bras. Ens. Fís., v. 26, n. 2: p. 355-366, ago. 2009. 
energy is presented. Some of the main purposes of an education project through comics are sketched. The present work is inserted in this project and it shows a set of seven original comic strips which can be used by High School teachers to talk about one of Einstein's revolutionary contributions to Modern Physics: Relativity.

Keywords: Space time; Physics; Science Education; Comics.

\section{Introdução}

Até o final do século XIX, o espaço e o tempo eram considerados absolutos e independentes um do outro. Admitia-se o tempo como universal e o espaço como formando um universo euclidiano e infinito. Para Isaac Newton (16421727), por exemplo, o espaço tinha um caráter divino ${ }^{[1]}$, admitido como o sensori$u m$ de Deus ${ }^{[2]}$.

Foi Albert Einstein (1879-1955) quem deu, em 1905, uma contribuição essencial à Física ${ }^{[3]}$, reformulando o conceito de Relatividade de Galileu e de Newton. Esta contribuição corresponde a uma nova visão de mundo ${ }^{[4-7]}$ e teve reflexos enormes na metodologia e no desenvolvimento da Física no século XX, no desenvolvimento tecnológico e, do ponto de vista físico-filosófico, introduz profundas modificações nos conceitos de espaço, tempo, massa e energia.

Explicar isso aos adolescentes faz parte de um desafio maior que vem preocupando pesquisadores e professores há algum tempo: como abordar temas de Física Moderna no Ensino Médio ${ }^{[8]}$. Neste trabalho, apresenta-se uma sugestão pontual, baseada em tirinhas feitas por um aluno da Oficina de Educação através de Histórias em Quadrinhos e Tirinhas - $\mathrm{EDUHQ}^{[9]}$-, mostrando que a linguagem dos quadrinhos pode dar suporte à abordagem de temas extra-curriculares. Em poucas palavras, a idéia básica da EDUHQ é aproveitar pontes entre Física e Arte $^{[10-11]}$ e a bagagem cultural dos participantes ${ }^{[12]}$. A metodologia utilizada na elaboração das tirinhas é simples e envolve a interação direta aluno/orientador, a leitura de textos e livros selecionados em torno de um tema previamente escolhido sendo que, como regra geral, a criação de qualquer tirinha só se dá após a clara compreensão do conceito envolvido da parte do aluno-artista. 


\section{A abrangência da teoria de Einstein}

O princípio galileano de absoluta equivalência entre dois sistemas inerciais de referência que se movem um em relação ao outro implica o abandono de qualquer possibilidade de movimento absoluto. Tal princípio é fruto e ao mesmo tempo a base de uma cosmovisão mecanicista que se estrutura com solidez a partir da Mecânica de Newton, fortemente calcada na causa efficiens - no conceito de força - que ocupa um lugar central na obra de Newton. No entanto, como bem salienta Steven Weinberg ${ }^{[13]}$, a partir da fusão da Relatividade com a Mecânica Quântica, não é mais a matéria (e, acrescentaríamos, a força) que ocupa uma posição central na nova Weltanschauung. Nela, o papel da matéria foi usurpado pelos princípios de simetria, dentre os quais destacamos os relacionados não mais apenas ao espaço, mas ao espaço-tempo.

O espaço no qual medimos distâncias e o tempo, que quantificamos com os relógios, não são nem absolutos nem independentes: eles estão unidos e formam um universo de quatro dimensões; é esse novo espaço-tempo que possui uma unidade física. As medidas de espaço e de tempo dependem, essencialmente, das condições de movimento dos observadores. Nessa nova Weltanchauung, que vai se sobrepor à newtoniana, é inegável a dupla contribuição de Einstein, ao fazer uma profunda revisão crítica do conceito de simultaneidade e ao tomar como paradigma da Física Teórica o Eletromagnetismo de James Clerk Maxwell (1831-1979), em vez da Mecânica de Newton. De fato, Einstein aceita como correta esta teoria e abandona as transformações de Galileu que expressam matematicamente o princípio da relatividade da Mecânica. Einstein deu, assim, ao princípio da relatividade, um alcance mais universal, estendendo-o aos fenômenos eletromagnéticos e a qualquer movimento.

Por fim, deve-se ressaltar o impacto da Relatividade na sociedade contemporânea. O desenvolvimento da eletrônica, por exemplo, só foi possível, em grande parte, graças à contribuição de Einstein e da Mecânica Quântica. O microcomputador e a revolução da informática, que ainda estamos vivendo, são frutos tecnológicos das ideias revolucionárias desse grande físico ${ }^{[14]}$.

Todos esses avanços influenciaram, de modo marcante, a sociedade em que vivemos. Esse fato, aliado à relevância do trabalho de Einstein motivou-nos no ano em que a UNESCO proclamou o Ano Internacional da Física, em comemoração ao centenário dos artigos seminais de Einstein - a refletir sobre como levar essas ideias aos jovens, em particular, aos alunos do Ensino Médio. O caminho escolhido foi o das tirinhas, pequenas histórias com dois ou três quadrinhos, como veremos a seguir. 


\section{A linguagem das tirinhas}

Apresentamos aqui uma resposta concreta à indagação de como levar este conteúdo de Física Moderna (Relatividade) aos jovens, afirmando que é possível levar para o aluno do Ensino Médio alguns aspectos da contribuição de Einstein ao conceito de espaço-tempo, utilizando a linguagem dos quadrinhos. Tal afirmação justifica-se pelo fato de as tirinhas aqui apresentadas terem sido desenvolvidas por um desses alunos, que não tinha conhecimento prévio sobre o assunto, e também por nossa experiência de utilizá-las em uma série de seminários para este segmento escolar, da qual apreendemos o valor facilitador de aprendizagem destas tirinhas.

Na verdade, esta não é nossa primeira experiência de disponibilizar conceitos de Física Moderna para o uso no Ensino Médio ${ }^{[15]}$. Nosso trabalho insere-se nas atividades da Oficina de Educação Através de Histórias em Quadrinhos e Tirinhas (EDUHQ), cuja sede é no Instituto de Física da Universidade do Estado do Rio de Janeiro ${ }^{[10]}$. O projeto multidisciplinar tem como meta principal o ensino de Ciências através de procedimentos didáticos não formais, que articulam conteúdos cognitivos e produção artística, através de uma raiz comum: a ênfase na criatividade operando no campo pedagógico ${ }^{[16]}$. seguintes $^{[10,16-17]}$

Detalhes sobre os objetivos da Oficina EDUHQ podem ser destacados os

- Priorizar uma pedagogia que contemple articulações entre ensino aprendizagem e conhecimento-sociedade, integrando metodologicamente os conteúdos das disciplinas curriculares, através da produção artística;

- Contribuir para que o aluno possa ser um ator importante na difusão do conhecimento, a partir de um processo que se inicia nos processos didáticos e culmina com seu ato criativo, processo esse que deverá lhe dar uma nova dimensão dialógica do processo ensino-aprendizado;

- Contribuir para o aprimoramento dos professores que participam do projeto, no tocante às técnicas e metodologias de ensino, bem como daqueles que, fora da oficina, posteriormente, terão contato com o material ali produzido, como agentes desencadeadores de outros processos criativos em situações diversas;

- Enfatizar e incentivar a produção artística não apenas como instrumento didático, mas como produção estética autônoma inserida na cultura e na sociedade;

- Criar e desenvolver técnicas e metodologias facilitadoras da transferência de conhecimentos na própria oficina, em sala de aula, através do ensino à 
distância e na vida prática, imprimindo à produção do conhecimento um aspecto lúdico e estético.

Gostaríamos apenas de ressaltar que, neste projeto, que existe há oito anos, pesquisadores, professores e alunos de graduação se revezam explicando conceitos básicos de diversas disciplinas aos alunos de Ensino Médio, dando aulas extraclasse de reforço dos conteúdos curriculares do Ensino Médio, ministrando palestras sobre assuntos variados e de interesse dos alunos, as quais, muitas vezes, abordam temas extracurriculares e de vanguarda no desenvolvimento da Ciência, como é o caso aqui relatado. Nessa abordagem, faz-se com que o ensino seja ministrado com base na valorização da experiência extraescolar, em consonância com os artigos $3^{\circ}$ e $26^{\circ}$ da LDB, que afirmam, respectivamente, que "ensino será ministrado com base [no princípio da] vinculação entre a educação escolar, o trabalho e as práticas sociais" e que "o ensino da arte constituirá componente curricular obrigatório, nos diversos níveis da educação, de forma a promover o desenvolvimento cultural dos alunos".

Em nosso caso, optamos pela manifestação artística através dos quadrinhos. O aluno, no projeto EDUHQ, atua como uma espécie de "tradutor". Ele não cria o conhecimento, mas, uma vez compreendido, o traduz na linguagem dos quadrinhos. Ao levarem em conta suas experiências pessoais e o bom humor típico dos jovens, os alunos criam um material didático inédito, com uma linguagem muito mais próxima das de seus coetâneos. Esse processo de produção e seu impacto sobre a motivação dos alunos já foi avaliado positivamente ${ }^{[18]}$ e pode ser facilmente reproduzido em sala de aula.

O que torna interessante o uso das Histórias em Quadrinhos como fonte de motivação para os alunos em seus estudos é justamente a sua forma e a sua linguagem características, que misturam elementos específicos e resultam em uma perfeita interação entre palavras e imagens. Em uma sociedade que passa por mudanças cada vez mais velozes e na qual a imagem se impõe de forma marcante, a rápida decodificação dos quadrinhos é um elemento facilitador do aprendizado, pois é fácil notar a diminuição do poder de concentração dos jovens em uma atividade específica, principalmente se ela diz respeito aos estudos. O leitor interessado pode consultar outros artigos e livros sobre como usar as tirinhas em sala de aula ${ }^{[19-24]}$

\section{As tirinhas}

Nesta seção apresentamos um conjunto de sete tirinhas originais que falam por si só, respectivamente, abordando temas como a unificação do espaço- 
tempo (tirinha 4), a relação entre massa e energia (tirinha 1), a dilatação temporal (tirinha 1) e uma última tirinha enfatizando que Einstein fez esse trabalho seminal com 26 anos.

O restante do material pode ser encontrado no site da EDUHQ, bem como um calendário em pdf com as 12 tirinhas feitas sobre esse assunto, que pode ser baixado gratuitamente ${ }^{[9]}$.

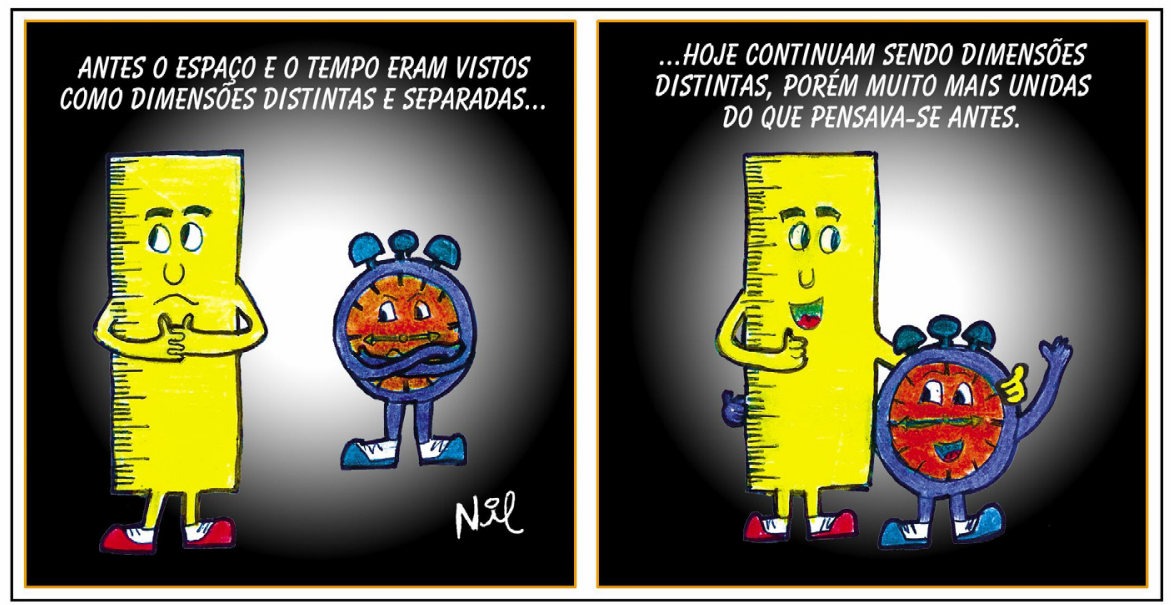

Tirinha 1

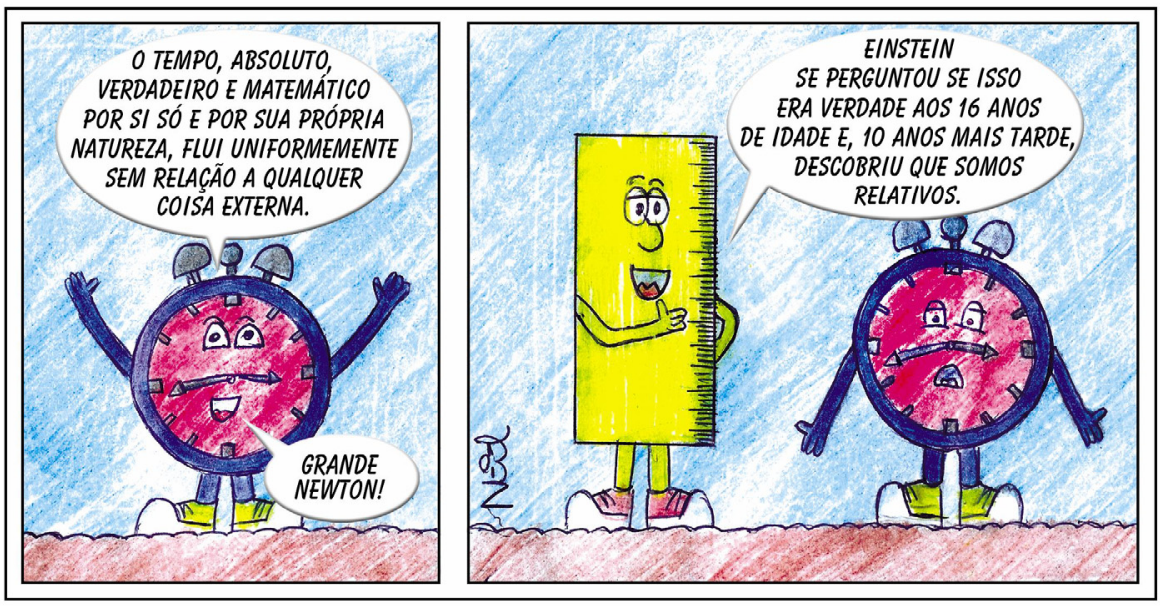

Tirinha 2 
Uma forma estimulante de utilizar as tirinhas em sala de aula é apresentá-la aos alunos como ponto de partida de sua explicação de um dado assunto. Podemos projetar a tirinha na parede, sem dizer nada sobre ela, e estimular os alunos a comentarem de que ela se trata. Algumas vezes nos surpreendemos com o resultado. Depois de um tempo de comentários livres, passamos a direcionar a discussão, dando à turma subsídios para compreender o conceito ao qual queremos nos referir. No caso da Relatividade, sugerimos começar pelo novo conceito de espaço-tempo (Tirinhas $1 \mathrm{e} 2$ ). Com elas o professor pode explicar inicialmente os conceitos clássicos de espaço e de tempo e, a partir daí a síntese de Einstein. Neste caso, as tirinhas 3 e 4 dão a dose de humor e uma informação histórica importante: Einstein era jovem quando fez a Relatividade.

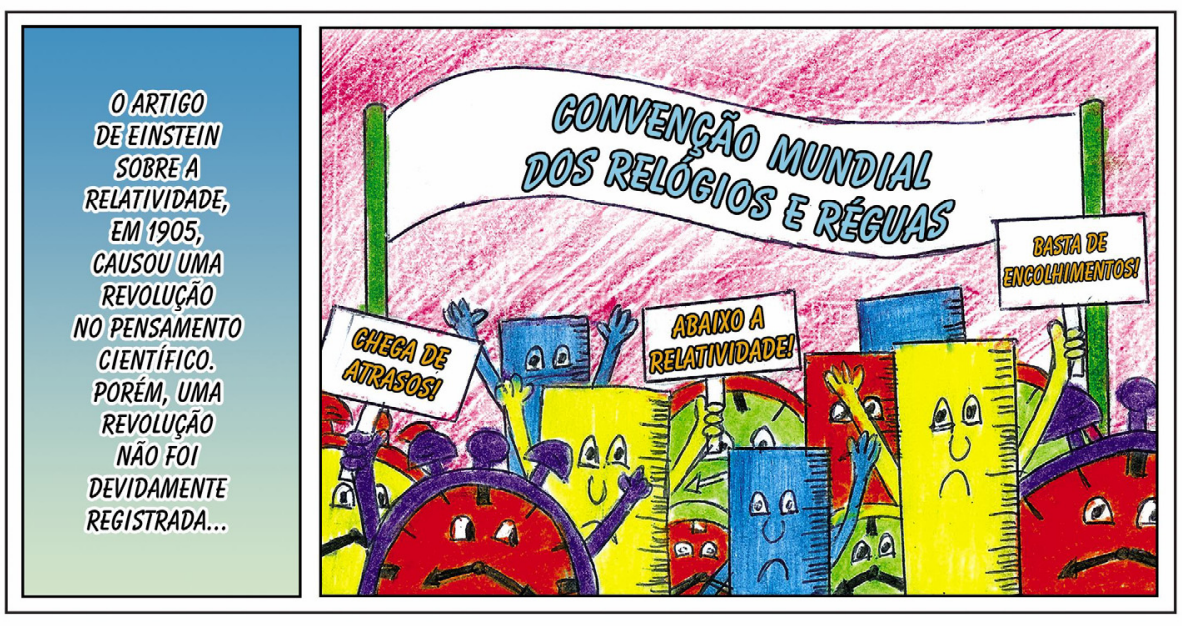

Tirinha 3 


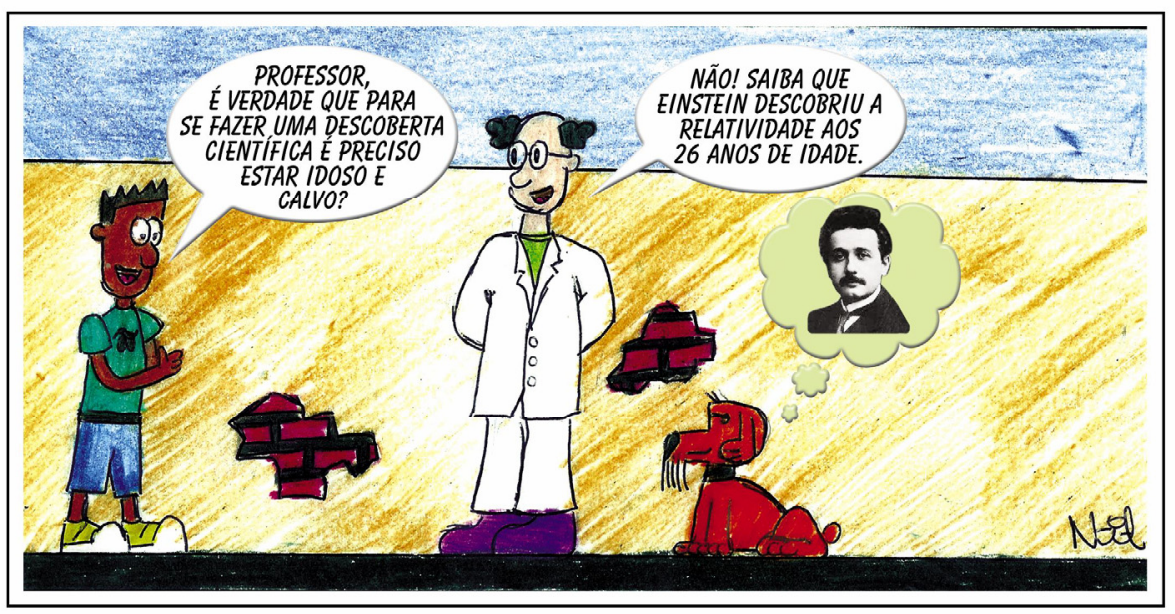

Tirinha 4

A Tirinha 5 serve como ponto de partida para de discutir as bases experimentais da Teoria da Relatividade Especial.

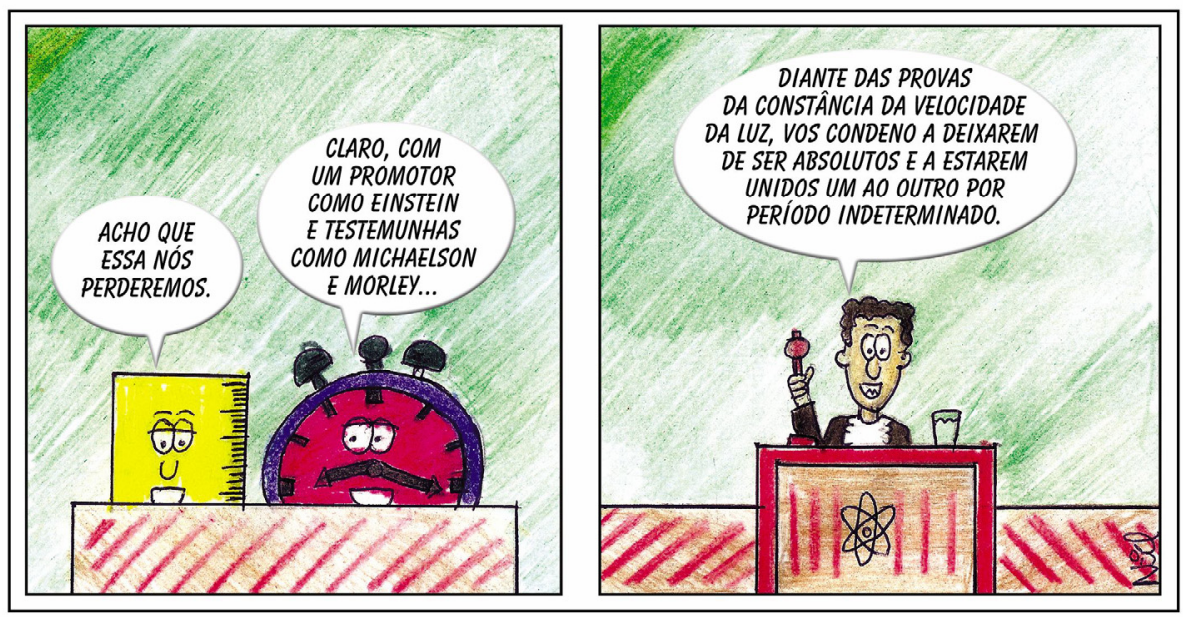

Tirinha 5 
Já a tirinha 6 coloca claramente a questão de que não foram apenas os conceitos de espaço e de tempo que se fundem em outro, mas também massa e energia, classicamente vistos como conceitos distintos, passam a estar interligados pela famosa fórmula $\mathrm{E}=\mathrm{mc}^{2}$.

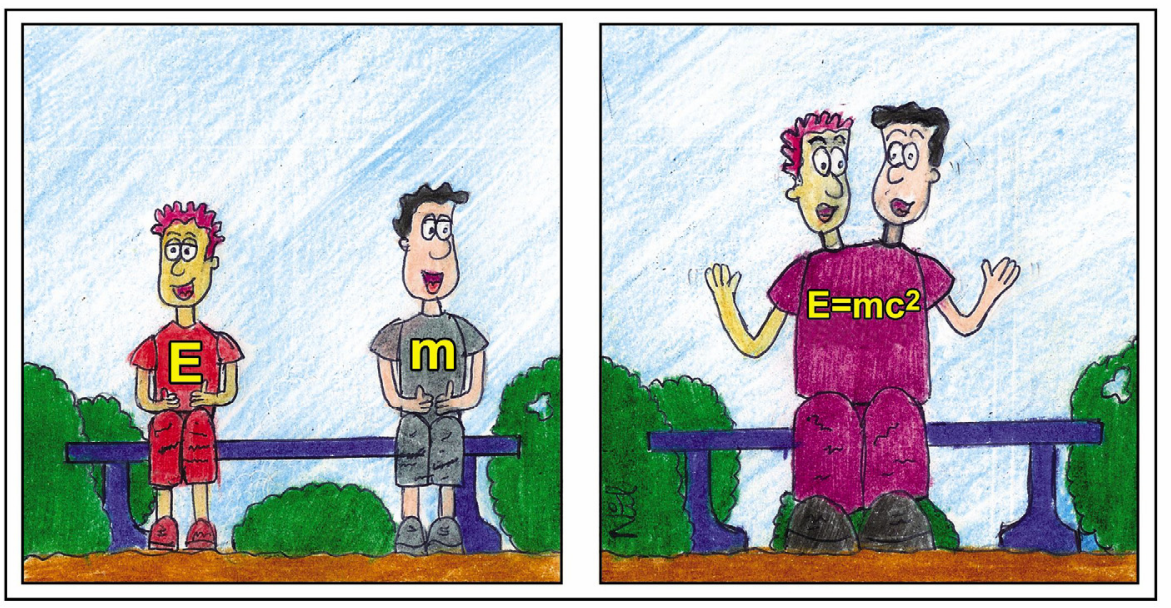

\section{Tirinha 6}

Caso tenhamos tempo, podemos aludir ao fato de que muitas partículas só conseguem chegar até nós por causa do conceito de dilatação temporal da relatividade, como é o caso dos múons cósmicos.

Alguns professores preferem apenas utilizar as tirinhas como ilustrações de suas aulas. Neste caso, elas são apresentadas ao aluno como uma situaçãoexemplo do que o professor ensinou de forma tradicional.

Qualquer que seja a forma de utilização, sugerimos que seja pedido aos alunos que façam novas leituras do que foi ensinado e do que eles ouviram na aula-discussão, através da elaboração de novas tirinhas. Essa tarefa pode ser para casa ou feita em sala de aula. Este ato criativo é importante, pois é por seu intermédio que o aluno reflete sobre um conhecimento novo e procura relacioná-lo com suas experiências prévias. 


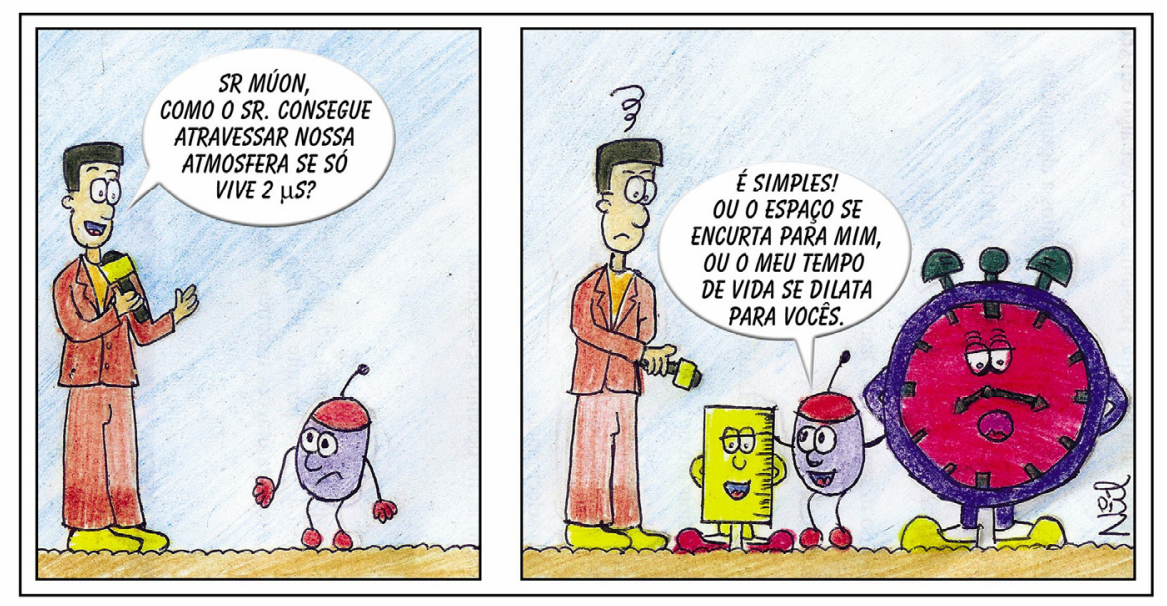

Tirinha 7

\section{Conclusões}

As tirinhas, por seu caráter lúdico, podem ser utilizadas pelo professor como instrumento de apoio em suas aulas capaz de "prender a atenção" dos alunos. Elas têm a vantagem de permitir que qualquer assunto de Física ou de Ciências possa ser abordado sem recorrer, num primeiro momento, à matematização do fenômeno. Levando-se em conta que muitas vezes é a deficiência em Matemática que desestimula o jovem a estudar ciências, recorrer aos quadrinhos pode ser uma decisão efetiva no sentido de motivar o estudante.

Neste artigo, mostramos que mesmo um tema de Física Moderna, como a Relatividade, pode ser abordado a partir de tirinhas. Mais ainda, mostramos que é viável que o jovem compreenda alguns conceitos básicos e os "traduza" na linguagem dos quadrinhos, como ilustra as tirinhas aqui reproduzidas, todas feitas por um único aluno de Ensino Médio.

\section{Agradecimentos}

Este projeto foi parcialmente apoiado pela FAPERJ. Os autores gostariam de agradecer a toda a equipe da Oficina EDUHQ e, em particular, a Erick Hoepfner, pelo auxílio na digitalização das tirinhas. Somos gratos a dois árbitros anônimos, cujos comentários e críticas contribuíram para maior clareza do texto. 


\section{Notas e Referências Bibliográficas}

${ }^{[1]}$ NEWTON, I. Optiks. London, 1704, Queries 28 and 31. Tradução: A.K.T. ASSIS. Óptica. Editora Edusp, 2002.

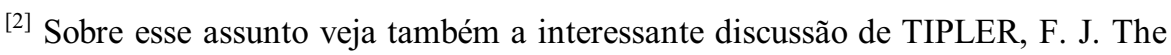
Sensorium of God: Newton and Absolute Spaces. In: COYNE, G. V.; HELLER, M.; ZYCINSKI, J. (Eds.). Newton and the new direction in Science. Vaticano: Specola Vaticana, 1988, p. 215-228.

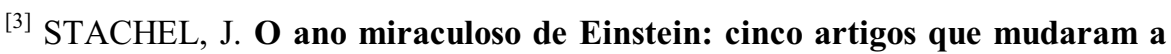
face da Física. Tradução: Alexandre Carlos Tort. Rio de Janeiro: Editora UFRJ, 2001.

${ }^{[4]}$ EINSTEIN, A. Relativity: the Special and General Theory (a popular exposition). New York: Wings Book, 1961.

[5] MILLER, A. I. Albert Einstein's Special Theory of Relativity: emergence (1905) and early interpretation (1905-1911). Reading: Addison-Wesley, 1981.

${ }^{[6]}$ TONNELAT, M. A. Histoire du principe de Relativité. Paris: Flammarion, 1971.

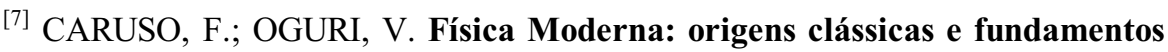
quânticos. Rio de Janeiro: Elsevier/Campus, 2006.

${ }^{[8]}$ Veja, por exemplo, OLIVEIRA, F. F.; VIANNA, D. M.; GERBASSI, R. S. Física moderna no Ensino Médio: o que dizem os professores. Revista Brasileira de Ensino de Física, v. 29, n. 3, p. 447-454, 2007 e referências lá citadas.

${ }^{[9]}$ Disponível em: <www.cbpf.br/eduhq>. Acesso em: 23 março 2009.

${ }^{[10]}$ CARUSO, F.; CARVALHO, M.; SILVEIRA, M. C. Uma proposta de ensino de divulgação de ciências através dos quadrinhos. Ciência \& Sociedade, dez. 2002.

${ }^{[11]}$ ZANETIC, J. Física e Arte: uma ponte entre duas culturas. Proposições, Campinas, v. 17, n. 1, p. 39-58, 2006.

${ }^{[12]}$ ZANETIC, J. Física é Cultura. Ciência e Cultura, São Paulo, v. 57, n. 3, p. 21-24, 2005. 
${ }^{[13]}$ WEINBERG, S. Dream of a final theory. New York: Pantheon Books, 1993.

${ }^{[14]}$ CARUSO, F. Relatividade. In: DA SILVA, F. C. T. et al. (Orgs.). Dicionário de Guerras e Revoluções do Século XX - As Grandes Transformações do Mundo: Conflitos, Cultura e Comportamento. Rio de Janeiro: Elsevier/Campus, 2004. p. 745-6.

${ }^{[15]}$ CARUSO, F.; DAOU, L. Tirinhas de Física. Rio de Janeiro, 2000-2002. v. 16. Ver também o site <www.cbpf.br/tirinhasdefisica>. Acesso em: 23 março 2009.

${ }^{[16]}$ CARUSO, F.; CARVALHO, M.; SILVEIRA, M. C. O. Ensino não-formal no campo das Ciências através dos Quadrinhos. Ciência \& Cultura v. 57, n. 4, p. 33-35, out.-dez. 2005. Veja

$<$ http://cienciaecultura.bvs.br/pdf/cic/v57n4/a19v57n4.pdf $>$.

${ }^{[17]}$ CARUSO, F.; SILVEIRA, C. Quadrinhos para a cidadania. História Ciências Saúde - Manguinhos. v. 16, n. 1, p. 217-236, jan.-mar. 2009.

${ }^{[18]}$ FREITAS, M. C. S. Da motivação e de sua relevância no processo de aprendizagem escolar. Monografia (curso de Pedagogia) - Faculdade de Educação e Letras da Universidade Iguaçu, Unig, Rio de Janeiro, 2002.

${ }^{[19]}$ PENA, F. L. A. Como trabalhar com 'tirinhas' na sala de aula. Física na Escola, São Paulo, v. 4, n. 2, p. 20-21, 2003.

${ }^{[20]}$ KAMEL, C.; LA ROCQUE, L. Quadrinhos como recurso didático em tópicos de biociências e Saúde. Enseñanza de las Ciencias, número extra, p.1-4, 2005.

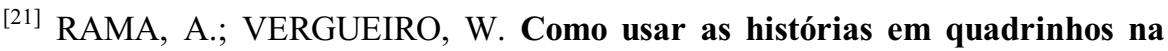
sala de aula. São Paulo: Editora Contexto, 2005.

${ }^{[22]}$ CARVAlHO, D. A Educação está no Gibi. São Paulo: Papirus, 2006.

${ }^{[23]}$ SCHWANCK, C.; CARUSO, F.; BIANCONI, M. L. Instrumentação para o Ensino de Ciências. Rio de Janeiro: Fundação Cecierj, 2006.

[24] GONICK, L.; HUFFMAN, A. Introdução Ilustrada à Física. São Paulo: Harbra, 1999. 